Vol. 6, No. 1, 2021

\title{
APPARATUS-TECHNOLOGICAL SCHEME OF TIN CANS SCRAP RECYCLING WITH OBTAINING TECHNICAL PRODUCTS
}

\author{
Valerii Dmitrikov ${ }^{1}$, Serhii Vakal ${ }^{2}$, Viktoriia Vakal ${ }^{2}$, Leonid Plyatsuk ${ }^{3}$ \\ ${ }^{1}$ Poltava State Agrarian Academy, \\ 1/3, Skovoroda Str., Poltava, 36003, Ukraine \\ ${ }^{2}$ Scientific-Research Institute of Mineral Fertilizers and Pigments of Sumy State University, \\ 2, Rymskogo-Korsakova Str., Sumy, 40000, Ukraine \\ ${ }^{3}$ Sumy State University, \\ 2, Rymskogo-Korsakova Str., Sumy, 40000, Ukraine \\ vsvakal@gmail.com
}

https://doi.org/10.23939/ep2021.01.033

Received: 14.12.2020

(C) Dmitrikov V., Vakal S., Vakal V., Plyatsuk L., 2021

\begin{abstract}
The article is devoted to the study of reducing the technogenic load on the environment due to the integrated processing of household metal scrap. A waste-free, resource saving, and environmentally safe method is proposed for extracting technical products from tin cans scrap - iron (III) oxide, tin (II) complex, suitable for further use, a mixture of ammonium and sodium nitrates as fertilizer for agriculture. As a result of theoretical and experimental studies, the direction of cans scrap recycling was selected with an assessment of the parameters and factors affecting the reagent process of scrap disposal. To verify the proposed method for can scrap processing in experimental studies, the reagent method and physical modeling were used together. The processes of the reagent can scrap recycling were studied in a laboratory installation. The results of studies on the reagent can scrap processing with the individual component allocation in the form of their derivatives are presented. A block diagram and a hardware-technological scheme for scrap processing with the receipt of technical products have been developed. The possibility of processing other metal-containing wastes according to the proposed scheme is shown.
\end{abstract}

Key words: iron, tin, reagent method, processing scheme, utilization.

\section{Introduction}

In recent years, the intensive mineral extraction to maintain a high level of technologies and industry development leads to a noticeable depletion of nonrenewable resources.

The increase in the technogenic load on the biosphere is largely influenced by the low level of production utilization and consumption waste, which does not exceed $8 \%$ with the total amount of waste reaching billions of tons (Protsenko et al., 2011).

The utilization problem of industrial and household waste in Ukraine is becoming more and more urgent, since these volumes are constantly growing, ahead of the introduced technologies for their utilization (Protsenko et al., 2017). Industrial and household wastes, which are stored annually at landfills, tailing dumps, and unplanned dumps, require the allotment of more and more areas and an increase in the existing storage sites, negatively affecting the biogeocenosis (Protsenko et al., 2011; Nigbur et al., 2010).

Modern requirements for the environmental safety of waste storage sites and trends in the socio-economic development of society are aimed at ensuring the sustainable development of various production, where one of the raw materials is the products of processing man-made waste.

The ecological and economic substantiation of the integrated use of secondary resources creates the preconditions for the development of technologies for industrial and household waste utilization and allows to reduce the shortage of natural raw materials due to its

For citation: Dmitrikov V., Vakal S., Vakal V., Plyatsuk L., 2020. Apparatus-technological scheme of tin cans scrap recycling with obtaining technical products. Journal Environmental Problems. Vol. 6, No. 1. p. 33-39. DOI: https://doi.org/10.23939/ep2021.01.033 
depletion (Afanasyeva et al., 2008; Bezfamilnaya et al., 2012; Giurco et al., 2014). In many countries, a secondary raw material industry has already been formed and is successfully developing, the main purpose of which is to provide the necessary raw materials for industrial enterprises, and, in some cases, to obtain target products from waste (Selivanova et al., 2011; Tarakanov, 2014; Giurco et al., 2014).

Another direction of waste processing is solid household waste disposal with the extraction of valuable resource components, which allows us to minimize their accumulation, preserve natural resources and reduce the harmful impact on the environment (Yavorskyi et al., 2014; Delo et al., 2018).

Both directions are significant in the educational process of environmental orientation (Ugulu, 2015).

Used tin cans (TC), which are thrown away together with household waste, are one of the household waste components since the problem of their separate collection and processing in Ukraine is still unresolved.

The environmental hazard of TC scrap is associated with the fact that in addition to iron it contains tin which has a high toxic, carcinogenic, and mutagenic effect on living organisms and the environment in general. This is indicated by the results of natural objects monitoring using modern research methods (Abdelrahman, 2015).

TC scrap recycling by pyrometallurgical methods does not allow tin extraction; during the TC scrap melting, tin is transformed into the iron melt (Chupakhin et al., 1974; Savov et al., 2003). It is also unreasonable to separate tin from waste electronic devices by pyrometallurgical methods (Khaliq et al., 2014). If aluminium cans are present in TC scrap, then aluminium is converted into slag when iron melts (Capuzzi et al., 2018; Markus et al., 2012).

However, TC scrap, when developing an effective technology for its processing, can also serve as a source of obtaining a wide range of valuable components, in particular, metals and their compounds, fertilizers (Tarasova, 2012), coagulants (Deena et al., 2019) thereby increasing the life cycle of technical products (Arena et al., 2016; Finnveden et al., 2009) by the provisions of the sustainable development concept.

The research aims at the development of an environmentally safe, resource-saving technology for a hardware-technological scheme for recycling TC scrap, with a return to the production of tin and iron in the form of their derivatives.

\section{Literature review}

A systematic approach to the conservation and reproduction of natural resources is a prerequisite for sustainable development. In this regard, complex solutions for the processing of secondary resources allow to increase the life cycle of raw materials extracted from the earth's depths and reduce the technogenic load on the environment (Castro et al., 2009; Dai et al., 2015; Finnveden et al., 2009).

Currently, industrialized countries have developed various methods for recycling metal scrap as secondary raw materials, all of which are differentiated by the type of metal and/or alloy, the presence and nature of impurities, the goals and objectives of processing. An example of this is the reagent processing of aluminium scrap to obtain a coagulant for the treatment of industrial effluents - polyaluminium chloride (Shakila, 2013; Deena et al., 2019). Based on the type of waste prevailing in a given region and taking into account the environmental component, one or another method of disposal is chosen.

An urgent task of modern society is also the implementation of a comprehensive technology for processing and utilization of waste from electroplating industries, which can pollute the environment with compounds of heavy metals (Protsenko et al., 2011; Selivanova et al., 2011). The latter include copper, nickel, chromium, cadmium, zinc, and others.

The technologies of electrodialysis, ion exchange, ultrafiltration, reverse osmosis, etc., which are energyintensive and require special equipment, have been developed to extract metals from electroplating industries sludge. The reagent method for recovering iron, copper, nickel-containing sludge from galvanic production presented in (Selivanova et al., 2011) is an environmentally safe, energy- and resource-saving technology.

Vacuum distillation, pyrometallurgical and hydrometallurgical technologies are used to extract lead, nickel, cadmium, zinc, mercury, silver, cobalt, and lithium oxides from waste power sources - accumulators and small power sources (batteries) to obtain valuable resource components.

However, an environmentally friendly and costeffective technology that would make it possible to recycle expired batteries into products of the appropriate quality has not been developed yet.

Today, the metal-containing waste recycling with the production of secondary metals and their derivatives is becoming more widespread in the world, and their share in the raw material structure is constantly increasing (Afanasyeva, 2008; Bezfamilnay, 2012; Castro et al., 2009; Dai et al., 2015; Tailoka et al., 2003).

This statement is also true for the disposal of a fairly significant household waste component, such as TC. In the traditional TC scrap remelting process, the most valuable component, tin, is irreversibly carried 
away. To remove the tin from ferrous scrap, a thermal separation method was used at a relatively high temperature of $700{ }^{\circ} \mathrm{C}$ (Lopez-Delgado et al., 2005).

For effective metal recycling, oxygen is also used in metallurgical methods to blow molten metal, which provokes chemical reactions that rid the melt of unnecessary impurities: sulfur and phosphorus. The required characteristics of secondary raw materials are also achieved due to the addition of other elements: cobalt, nickel, chromium, and vanadium.

An increase in the target product yield in metallurgical methods is also achieved by the use of fluxes, as, for example, in the production of aluminium from TC scrap (Shakila, 2013). However, thermal methods, due to their high energy consumption and harmful effects on the environment, are increasingly being replaced by electrochemical and chemical methods (Kuntyi et al., 2006; Savov et al., 2003; White et al., 2012).

The electrolytic method is realized when extracting tin from waste tinplate using stannate alkaline electrolytes, in which sponge tin is obtained. The chemical method is used in an alkaline electrolyte under the action of an oxidizing agent (methanitrobenzoic acid) with the simultaneous deposition of tin in the form of a dense metal, in which metal tin is obtained directly.

Another option for removing the tin coating from pre-crushed and deformed tinplate waste is the reagent leaching method with $\mathrm{NaOH}$ solution which occurs at a temperature of $70^{\circ} \mathrm{C}$. The process of complete tin coating removal from the surface of the tinned sheet under such conditions occurs in 30-35 min (Kurylets et al., 2013). Along with this, electrolysis-free removal of a thin tin coating from tinplate waste in sodium hydroxide solutions with periodic dipping into a $\mathrm{NaOH}$ solution, as studies show, occurs by an electrochemical mechanism at a temperature of $65-75^{\circ} \mathrm{C}$ (Kuntyi et al., 2006).

Along with the development of technologies, the hardware process design is also being improved (Kurylets et al., 2013). However, the high energy costs, low efficiency, and relatively high toxicity of these methods make these methods of TC scrap recycling uncompetitive.

The most promising reagent method for converting TC scrap into a dissolved state is the use of nitrate acid, the salts of which are highly soluble, which makes the TC recycling process real and effective.

At present, despite a slight global decrease in tinplate consumption along with a decrease in the tin coating thickness, interest in efficient TC scrap recycling remains high. This is especially typical for countries lacking tin raw materials, where the environmental and economic aspects of solving the problem of the TC scrap recycling are especially relevant (Bezfamilnay, 2012; Protsenko et al., 2011).

\section{Experimental part}

To develop an environmentally safe, resourcesaving technology for TC scrap recycling, it was necessary to solve the following problem: develop technology based on the results of laboratory experiments [Protsenko et al. 2017], and then a hardwaretechnological scheme for TC scrap recycling with the extraction of technical products - derivatives of tin and iron.

The achievement of this goal was carried out by theoretical and experimental studies, which made it possible to choose the direction of TC scrap recycling with an assessment of the parameters and factors of influence on the reagent TC scrap recycling process. In experimental studies, a reagent method and physical modelling were used together to verify the proposed method for TC scrap processing.

The reagent method proposed and developed for the TC scrap processing is based on the differences in the chemical properties of tin, iron, and their compounds. The reagent TC scrap processing proceeded in stages and included physical and chemical methods, as well as technological methods, for example, acid-base treatment, crystallization, filtration, evaporation, and calcination (Fig. 1). Various analytical instrumental methods were also used.

The processes of reagent TC scrap processing were studied on a laboratory installation which comprised a five-necked flask, a paddle stirrer with an electric motor, a dropping funnel, a reflux condenser, a temperature reaction mixture sensor, a compressor feed capillary with an airflow sensor, and a heating element. The installation was also equipped with a control unit, which includes a power supply unit and a measurement unit for controlling the heating and aeration processes during the laboratory research.

First, TC scrap was prepared for recycling, separated from non-magnetic impurities and obvious contaminants, washed with water, removed the protective coating, labels, varnish, and degreased. The discrepancy in weight before and after preparation of the TC scrap for processing was insignificant. Pre-crushed TC scrap was placed in a five-necked flask equipped with a paddle stirrer with an electric motor. Diluted nitrate acid was added to the flask with stirring from a dropping funnel until the TC scrap was completely dissolved.

At the next stage, an aqueous solution of a mixture of tin, iron, and ammonium nitrates was treated with a stoichiometric sodium hydroxide amount, passing an excess air amount into the solution with stirring. 
The suspension of crystals was filtered off, obtaining a precipitate in the form of a mixture of Stannum (II) and Ferrum (III) hydroxides and the filtrate, a solution of sodium and ammonium nitrates. The filtrate, after evaporation on a rotary evaporator, formed a technical mixture of sodium and ammonium nitrate crystals.

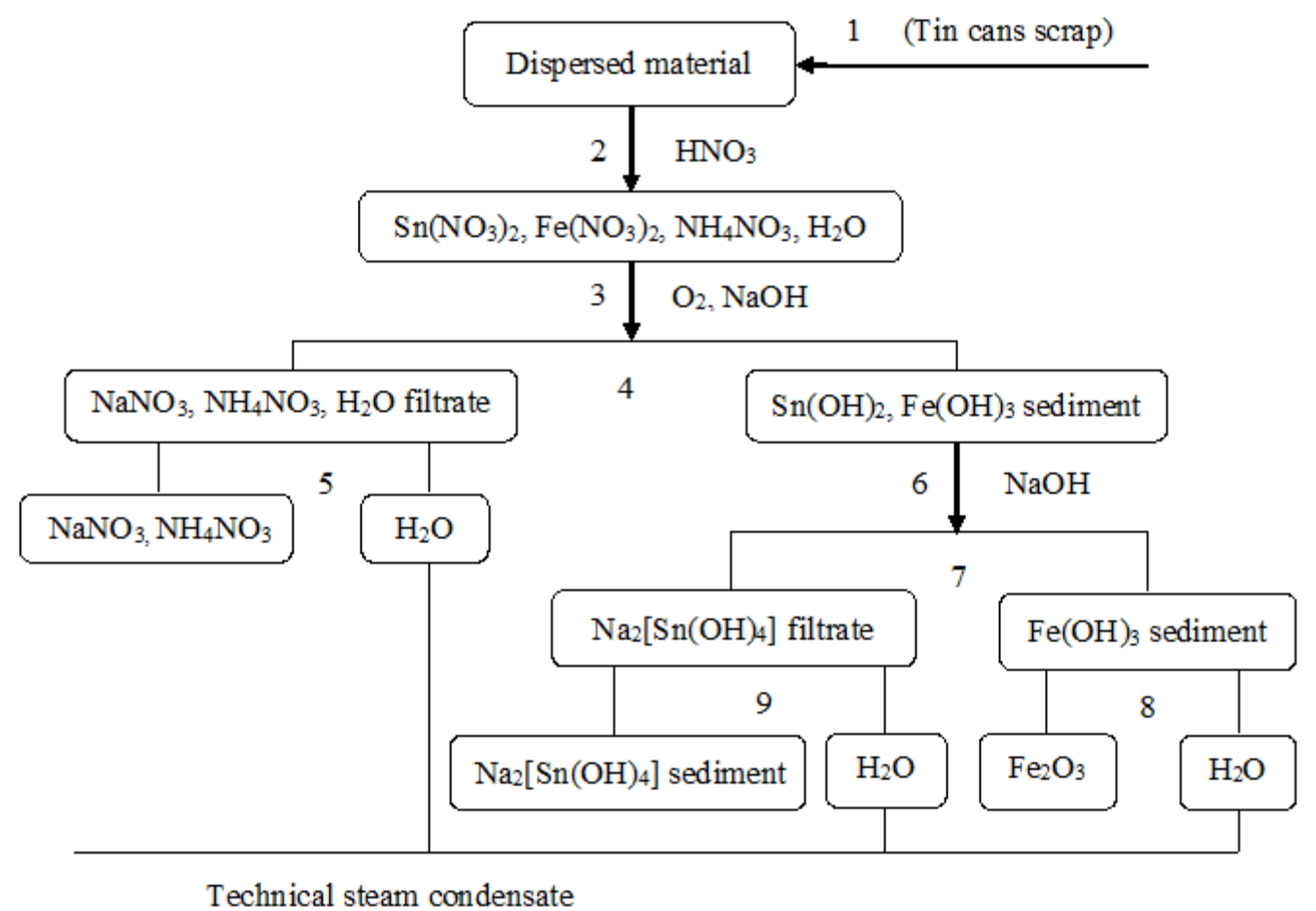

Fig. 1. Scheme of reagent processing of TC scrap:

1 - preparation and grinding of TC scrap, 2 - dissolution, 3 - oxidation, 4, 7 - filtration, 5 - evaporation, $6-\mathrm{NaOH}$ treatment, 8 - drying / calcination, 9 - drying

The Stannum (II) and Ferrum (III) hydroxides precipitate were dissolved in an excess of sodium hydroxide.

The resulting suspension of crystals was filtered off to obtain a Ferrum (III) hydroxide precipitate, which was evaporated, dried, and calcined in a muffle furnace to obtain Ferrum (III) oxide. The filtrate containing sodium tetrahydroxostannate (II) was evaporated on a rotary evaporator to obtain the target substance, tin, in a dry form.

The control of the feedstock composition and disposal products was carried out using modern methods of analysis and metrological requirements.

The expected factors of influence on the processes proceeding in the flask under the reagents influence were the stirring rate and temperature, however, their influence during the reagent processing of TC scrap was insignificant.

\section{Results and Discussion}

Based on the results obtained in laboratory conditions, a hardware-technological scheme for the reagent TC scrap disposal has been developed (Fig. 2).
The determining factors in the development of a technological scheme for TC scrap processing are environmental, technical, economic, and social factors.

The scheme includes standard equipment the operating parameters of which are calculated by the known techniques contained in special literature (Deena et al., 2019; Pande et al., 2015).

At all sections of the TC scrap recycling, full technological operation mechanization should be used with the transition of the entire line for the TC scrap processing to the automatic mode. It should also provide for the possibility of adjusting the parameters of the technological line in a wide range using the software.

After preliminary cleaning, TC scrap prepared for processing is loaded into the measuring tank 1 , then it goes to crusher 2, and the dispersed material gets to feeder hopper 3 and then to conveyor 4 , and finally into measuring tank 5 .

In reactor 6, equipped with a stirrer with an electric drive, dispersed TC scrap from measuring tank 5 and diluted nitrate acid from measuring tank 7 in the required amount are fed. As a result of TC scrap dissolution, a mixture of various nitrates is formed, which then enters 
reactor 8 , equipped with an electric stirrer. The required amount of sodium hydroxide and air from compressor 9 are fed into it from measuring tank 10.

As a result of the chemical processes, an aqueous suspension is formed, which is separated on decanter 11 (decanter centrifuge, for example, by Alfa Laval, Westfalia Separator, Haus, Broadbent). The filtrate is subjected to evaporation in apparatus 12 and drying in apparatus 13, after which a mixture of sodium and ammonium nitrates arrives at the warehouse.

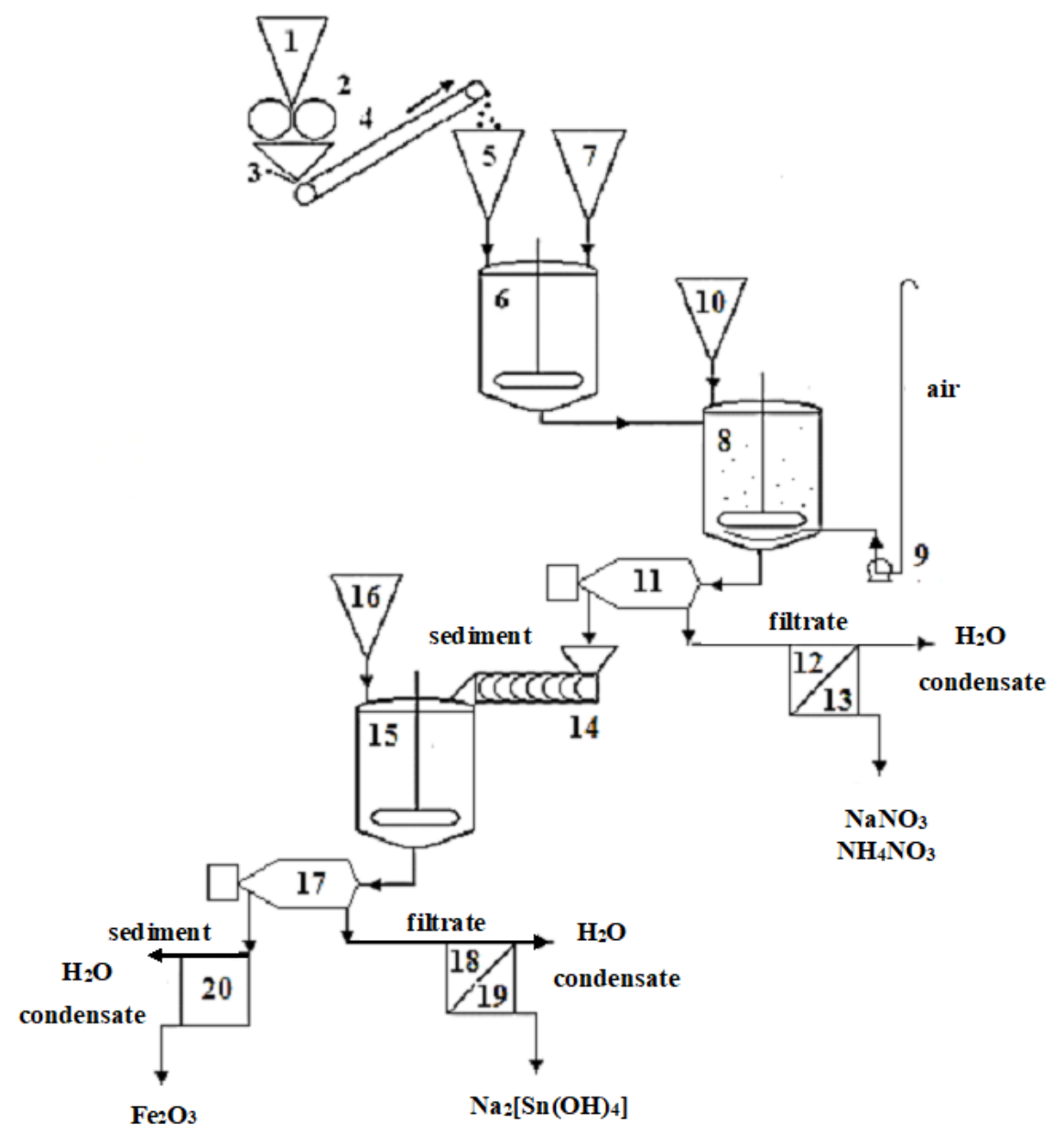

Fig. 2. Hardware-technological scheme for the TC scrap processing: 1 - measuring tank, 2 - crusher, 3 - feeding hopper, 4 - conveyor, 5, 7, 10, 16 - measuring tanks, $6,8,15$ - reactors, 9 - compressor, 11,17 - decanter centrifuges, 12,18 - evaporators, $13,19,20$ - dryers, 14 - screw feeder

The precipitate is removed from decanter centrifuge 11 and screw feeder 14 is fed into reactor 15 equipped with an electric stirrer. This also receives the required Sodium hydroxide amount from measuring tank 16.

Upon the reaction completion, the aqueous suspension is fed to decanter centrifuge 17. The filtrate is subjected to evaporation in apparatus 18 and drying in apparatus 19, after which disodium Stannum (II) tetrahydroxide is fed to the warehouse.

The precipitate is removed from decanter 17 and fed to dryer 20, and the dry product - Ferrum (III) oxide is fed to the warehouse. Condensate of demineralized water obtained in the process of evaporation and drying is used for technical purposes and/or raw materials preparation for processing.

\section{Conclusions}

The expediency of the step-by-step selective separation of tin from iron in the form of their derivatives with the receipt of technical products is shown. The developed technology and instrumental-technological scheme of TC scrap recycling, like the method itself, is waste-free, environmentally safe, and resource-saving.

Tin cans recycling according to the indicated scheme allows obtaining:

- sodium tetrahydroxostannate (II), used as a reducing agent in organic synthesis,

- Ferrum (III) oxide for technical use,

- ammonium and sodium nitrates (fertilizer for agricultural crops), 
- combined steam condensates for technological needs.

The authors recommend considering the developed method and technology scheme for industrial application. With additional modification, this technology can be applied for processing other types of scrap containing tin, for example, spent lead-tin batteries.

\section{References}

Abdelrahman, N. A. (2015). Tin-Plate Corrosion in Canned Foods. Journal of Global Biosciences, 4 (7), 2966-2971.

Afanasyeva, T. A. (2008). Feasibility study for the development of an integrated production reliability management system. Modern high technology, (3), 49-54. [in Russian]

Arena, N., Sinclair, P., Lee, J., \& Clift, R. (2016). Life cycle engineering of production, use and recovery of self-chilling beverage cans. Journal of Cleaner Production, 142 (4), 1562-1570. doi: https://doi.org/10.1016/j.jclepro. 2016.11.148

Bezfamilnaya, E. V. (2012). Increasing environmental and economic efficiency while improving production technologies. Bulletin of SRSTU (NPI), (5), 83-89. [in Russian]

Capuzzi, S., \& Timelli, G. (2018). Preparation and Melting of Scrap in Aluminum Recycling: A Review. Metals, 8, 249. doi: https://doi.org/10.3390/met8040249

Castro, P., Garrido, M., Reis, E., \& Menezes, J. (2009). Ambivalence and conservation behavior: An exploratory study on the recycling of metal cans. Journal of Environmental Psychology, (29), 24-33. doi:https://doi.org/ 10.1016/j.jenvp.2008.11.003

Chupakhin, V. M., \& Leonov, I. T. (1974). Production of tin can containers. Moscow: Food industry. [in Russian]

Dai, Y., Gordon, M., Ye, J., Zu, D., Lin, Z., Robinson, N., Woodard, R., \& Harder, M. (2015). Why door-stepping can increase household waste recycling. Resources, Conservation, and Recycling, (102), 9-19. doi:https://doi.org/10.1016/j. resconrec.20-15.06.004

Deena, H., Khadeeja, P., Leena, P. K. Fahmi, Lekshmi, J. S., \& Sreekumar, N. (2019). Production of Industrial Coagulant (Poly Aluminium Chloride) From Used Beverage Cans. Journal of Scientific \& Industrial Research, 78 (07), 448453.

Delo, A., Tabbaa, D., \& Arwana, A. (2018). Study of Management for Household Waste. International Journal of Recent Scientific Research, 9, 11 (E), 29781-29783. doi: http://dx.doi.org/10.24327/ijrsr.2018.0911.2913

Finnveden, G., Hauschild, M. Z., Ekvall, T., Guinée, J., Heijungs, R., Hellweg, S., Koehler, A., Pennington, D., \& Suh, S. (2009). Recent developments in Life Cycle Assessment. Journal of Environmental Management, (91), 1-21. doi: https://doi.org/10.1016/j.jenvman. 2009.06.06.018

Giurco, D., Litttleboy, A., Boyle, T., Fyfe, J., \& White, S. (2014). Circular Economy: Questions for Responsible
Minerals, Additive Manufacturing and Recycling of Metals. Resources, (3), 432-453. doi:https://doi.org/ 10.3390/resources3020432

Khaliq, A., Rhamdhan, M. A., Brooks, G., \& Masood, S. (2014). Metal extraction processes for electronic waste and existing industrial routes: a review and Australian perspective. Resources, (3), 152-179. doi:http://doi.org/ 10.3390/resources3010152

Kuntyi, O. I., Kurylets, O. G., Bilan, O. I., \& Zatyrach, R. I. (2006). Non-electrolytic removal of thin tin coatings from white tin waste in sodium hydroxide solutions. Ecotechnologies and Resource Saving, (2), 49-51. [in Ukrainian]

Kurylets, O. G., Znak, Z. O., \& Savchuk, L. V. (2013). Leaching of tin from the waste of white tin in the drum apparatus. Energy Technologies and Resource Saving, (6), 43-49. [in Ukrainian]

Lopez-Delgado, A., Lobo-Recio, M., Pena, C., Lopez, V., \& Lopez, F. (2005). Characteristics and thermal detinning of ferrous scrap from Spanish MSW compost plants. Resources, Conservation and Recycling, 44, 167-183. doi: https://doi.org/10.1016/j.resconrec.2004.11.003

Markus, A. Reuter, Ilkka, \& V. Kojo. (2012). Challenges of metals recycling. Materia, (2), 50-57.

Nigbur, D., Lyons, E., \& Uzzell, D. (2010). Attitudes, norms, identity and environmental behavior: Using an expanded theory of planned behavior to predict participation in a kerbside recycling program. British Journal of Social Psychology, 49, 259-284. doi:https://doi.org/10.1348/ 014466609X449395

Olshanskaya, L. N., Bulkina, L. A., Lazareva, E. N., Egorov, V. V., \& Shaykhiyev, I. G. (2014). Technological aspects of the recovery of toxic metals from galvanic waste for secondary use. Bulletin of Kazan Technological University (KTU), 17(7), 195-199. [in Russian]

Pande, R. M., Kandharkar, S. U., \& Patthe, R. B. (2015). Computational Fluid Dynamics (CFD) of Centrifugal Pump to Study. International Journal on Theoretical and Applied Research in Mechanical Engineering, 2 (4), 59-62.

Protsenko, A. V., Dmitrikov, V. P., Gunko, S. A., Egunko, V. V. (2011). On compliance with environmental standards in the disposal of sludge from spent manganese-zinc galvanic cells. Proceedings of the National Mining University, 36(2), 218-223. [in Ukrainian]

Protsenko, A. V., Gulyayev, V. M., Anatskiy, A. S., \& Dmitrikov, V. P. (2017). Reagent hydrochemical method for the extraction of tin from scrap tin cans. Proceedings of DDTU (Chemical technology. Biotechnology), 2(31), 113117. [in Ukrainian]

Savov, L., Volkova, E., \& Janke, D. (2003). Cooper and Tin in Steel Scrap Recycling. RMZ - Materials and Geoenvironment, 50 (3), 627-640.

Selivanova, N. V., Trifonova, T. A., \& Shirkin, L. A. (2011). Utilization of galvanic production waste. Bulletin of the Samara Scientific Center of the Russian Academy of Sciences, 1 (8), 2085-2088. [in Russian]

Shakila, B. (2013). Recycling of Aluminium from Aluminium Cans. J. Chem. Soc. Pak., 35, 6, 1490-1493. 
Tailoka, F., Kumar, R. V., \& Fray, D. J. (2003). Mechanism of chlorination of tin in air and its application to steel can recycling. Ironmaking and Steelmaking, 30, 5, 391-395. doi: https://doi.org/10.1179/030192303225004033

Tarakanov, V. A. (2014). Recycling industry: supply and demand. Municipal solid waste, (1), 38-42. [in Russian]

Tarasova, G. I. (2012). A rational method for producing a pigment filler from metal-containing industrial waste. Bulletin of BSTU named after V. G. Shukhov, (2), 128-132. [in Russian]

Ugulu, I.. (2015). A quantitative investigation on recycling attitudes of gifted/talented students. Biotechnology \&
Biotechnological Equipment, 29:sup1, S20-S26. doi: https://doi.org/10.1080/13102818.2015.1047168

White, K. M., \& Hyde, M. K. (2012). The Role of Self-Perceptions in the Prediction of Household Recycling Behavior in Australia. Environment and Behavior, 44 (6), 785-799. doi:https://doi.org/10.1177/ 0013916511408069

Yavorskyi, V. T., Zozulia, G. I., \& Bukliv, R. L. (2014). Utilization of valuable components from waste small electric sources. Bulletin of National University "Lviv Polytechnic": Chemistry, technology of substances and their application, 787, 117-121. [in Ukrainian] 